\title{
Neutrophil priming by hypoxic preconditioning protects against epithelial barrier damage and enteric bacterial translocation in intestinal ischemia/reperfusion
}

\author{
Yen-Zhen Lu' ${ }^{1}$, Chi-Chin Wu ${ }^{1}$, Yi-Chen Huang ${ }^{1}$, Ching-Ying Huang ${ }^{1}$, Chung-Yi Yang ${ }^{2}$, Tsung-Chun Lee ${ }^{3}$, \\ Chau-Fong Chen ${ }^{1}$ and Linda Chia-Hui $\mathrm{Yu}^{1}$
}

Intestinal ischemia/reperfusion (I/R) induces mucosal barrier dysfunction and bacterial translocation (BT). Neutrophilderived oxidative free radicals have been incriminated in the pathogenesis of ischemic injury in various organs, but their role in the bacteria-containing intestinal tract is debatable. Primed neutrophils are characterized by a faster and higher respiratory burst activity associated with more robust bactericidal effects on exposure to a second stimulus. Hypoxic preconditioning (HPC) attenuates ischemic injury in brain, heart, lung and kidney; no reports were found in the gut. Our aim is to investigate whether neutrophil priming by HPC protects against intestinal I/R-induced barrier damage and bacterial influx. Rats were raised in normoxia (NM) or kept in a hypobaric hypoxic chamber (380 Torr) $17 \mathrm{~h} /$ day for 3 weeks for HPC, followed by sham operation or intestinal I/R. Gut permeability was determined by using an ex vivo macromolecular flux assay and an in vivo magnetic resonance imaging-based method. Liver and spleen homogenates were plated for bacterial culturing. Rats raised in HPC showed diminished levels of BT, and partially improved mucosal histopathology and epithelial barrier function compared with the NM groups after intestinal I/R. Augmented cytokineinduced neutrophil chemoattractant (CINC)-1 and -3 levels and myeloperoxidase activity correlated with enhanced infiltration of neutrophils in intestines of HPC-I/R compared with NM-I/R rats. HPC alone caused blood neutrophil priming, as shown by elevated production of superoxide and hydrogen peroxide on stimulation, increased membrane translocation of cytosolic $\mathrm{p} 47^{\text {phox }}$ and $\mathrm{p} 67^{\text {phox }}$, as well as augmented bacterial-killing and phagocytotic activities. Neutrophil depletion reversed the mucosal protection by HPC, and aggravated intestinal leakiness and BT following I/R. In conclusion, neutrophil priming by HPC protects against I/R-induced BT via direct antimicrobial activity by oxidative respiratory bursts and through promotion of epithelial barrier integrity for luminal confinement of enteric bacteria. Laboratory Investigation (2012) 92, 783-796; doi:10.1038/labinvest.2012.11; published online 27 February 2012

KEYWORDS: bacterial translocation; epithelial permeability; hypoxic preconditioning; intestinal barrier function; mesenteric ischemia; neutrophil priming; respiratory burst activity

Intestinal ischemia/reperfusion ( $\mathrm{I} / \mathrm{R})$ injury and hypoxic stress are seen in patients with mesenteric artery embolism, traumatic or hemorrhagic shock, and inflammatory bowel disease; they are also of concern for those undergoing major abdominal and cardiovascular surgery. ${ }^{1-3}$ Intestinal I/R may trigger mucosal barrier damage and enteric bacterial translocation (BT), leading to development of septic complications. ${ }^{4,5}$

The intestine contains over 100 trillion commensal bacteria that are normally restricted to the lumen. ${ }^{6,7}$ Germ-free rodents subjected to mesenteric $\mathrm{I} / \mathrm{R}$ exhibited less intestinal and lung histopathology, and showed higher survival rates than conventionally raised animals, underscoring the role of enteric bacteria in the pathogenesis of I/R-induced local and remote organ dysfunction. ${ }^{8}$ The barrier function of the gut relies on tightly linked epithelial layers and underlying innate immune cells in the lamina propria. Once the epithelial barrier is breached, the activation of neutrophils provides an innate defense against the invading pathogens. Circulating neutrophils

\footnotetext{
${ }^{1}$ Graduate Institute of Physiology, National Taiwan University College of Medicine, Taipei, Taiwan, ROC; ${ }^{2}$ Department of Medical Imaging, National Taiwan University Hospital, Taipei, Taiwan, ROC and ${ }^{3}$ Division of Gastroenterology, Department of Internal Medicine, National Taiwan University Hospital, Taipei, Taiwan, ROC

Correspondence: Associate Professor LC-H Yu, PhD, Graduate Institute of Physiology, National Taiwan University College of Medicine, Suite 1020, \#1 Jen-Ai Road. Section I, Taipei 100, Taiwan, ROC.

E-mail: Ichyu@ntu.edu.tw
}

Received 15 July 2011; revised 19 December 2011; accepted 29 December 2011 
infiltrate rapidly to peripheral sites on tissue injury to engage in phagocytosis and produce free radicals for bactericidal effects. $^{9-11}$ In contrast to sterile visceral organs where neutrophil activation is considered harmful to post-ischemic tissues, ${ }^{12-14}$ sufficient activation of phagocytes in the gut mucosa may have critical roles in curbing the invasion of enteric bacteria. In line with this thought, novel therapies that strengthen the epithelial and/or immune barrier to inhibit BT may be useful in reducing intestinal $\mathrm{I} / \mathrm{R}$ injury.

Hypoxic preconditioning (HPC) is defined as the phenomenon whereby exposure of animals or cells to intermittent hypoxia protects them against a sustained period of subsequent ischemia. Clinical evidence indicates that individuals living at high altitudes show lower mortality rates of coronary heart disease and stroke compared with those living at sea levels. ${ }^{15}$ Training protocols employing intermittent exposure to hypobaric hypoxia also provided beneficial effects to the cardiac and respiratory systems for stronger sports performance. ${ }^{16,17} \mathrm{Nu}$ merous animal studies have documented that HPC protects the heart, brain, kidney and lung against $\mathrm{I} / \mathrm{R}$ injury. ${ }^{18-21}$ Other reports have indicated that adaptive hypoxia protects the intestinal epithelial barrier integrity via transcriptional regulation of hypoxia-inducible factor 1 in experimental colitis models. ${ }^{22-24}$ It remains unclear whether HPC attenuates mesenteric I/R-induced intestinal mucosal injury and BT.

Neutrophil activation and free radical production act as double-edge swords that are responsible for microbial clearance and may induce bystander tissue injury. Although previous literature implicates neutrophil activation as a cause of gut reperfusion injury, ${ }^{25,26}$ others have shown contradictory data in which depletion of neutrophils fails to attenuate mucosal histopathology in intestinal I/R and experimental colitis models. $^{27,28}$ Other reports also argue against the initiating role of neutrophils in gut tissue damage since the onset of mucosal destruction occurs before neutrophil infiltration. $^{29,30}$ These findings suggest that neutrophil activation is secondary to intestinal barrier defects and BT, supposedly to engage in antimicrobial activities. It is noteworthy that despite extensive research for over two decades on oxygen-free radicals and neutrophils, clinical trials of antioxidants or antineutrophil therapy have not had much success in reducing $I / R$ injury in various organs. ${ }^{31-34}$

Oxidative respiratory bursts in neutrophils are characterized by the production of superoxide, hydrogen peroxide and hypochlorous acids. The synthesis of free oxidative radicals is catalyzed by nicotinamide adenine dinucleotide phosphate $(\mathrm{NADPH})$ oxidase and myeloperoxidase (MPO). ${ }^{9,10} \mathrm{Neu}-$ trophil activation is a finely tuned two-step mechanism in which circulating quiescent cells becomes primed before complete activation. Primed neutrophils mount faster and higher responses of respiratory burst activity on exposure to a second stimulus. ${ }^{35}$ Enhanced phosphorylation and translocation of NADPH oxidase subunits, including $\mathrm{p} 47^{\text {phox }}$ and $\mathrm{p} 67^{\text {phox }}$ from cytosol to plasma or granular membrane were found in primed neutrophils. ${ }^{10}$ In rats, the infiltration of neutrophils to peripheral tissues follows the gradient of rat cytokine-induced neutrophil chemoattractant (CINC)-1 (a homolog of human IL-8) and CINC-3 (a homolog of human GRO $\gamma){ }^{36}$ Based on previous findings that whole body hypoxia induces a priming effect on neutrophils for enhanced superoxide production, endothelial adherence and membrane receptor expression, ${ }^{37-39}$ we hypothesized that neutrophil priming may be involved in HPC-mediated protection against intestinal I/R-induced barrier dysfunction and BT.

\section{MATERIALS AND METHODS Hypoxic Preconditioning}

Male Wistar rats (150-200g) obtained from the Animal Center of NTUCM were housed in a temperature-controlled room with 12-h light-dark cycles, and fed regular rat chow and water. All experiments described herein were conducted with the approval of the Institutional Animal Care and Use Committee, NTUCM.

Rats were exposed to an intermittent hypoxic condition for $17 \mathrm{~h} /$ day (1600 to 0900 hours) in a hypobaric hypoxic chamber equal to $5500 \mathrm{~m}$ in altitude $(380 \mathrm{~mm} \mathrm{Hg}$, equivalent to $10 \%$ normobaric oxygen) for 21 days. Age-matched normoxic controls were kept at sea level. This method of HPC was previously established as one to which most rats can adapt successfully. ${ }^{40,41}$

\section{Intestinal I/R}

Rats exposed to normoxia (NM) and HPC were divided to three subgroups each: one group was killed directly as controls (cont), and the second and third groups underwent surgical procedures of either sham operation (sham) or intestinal I/R. After fasting overnight, rats were anesthetized by intraperitoneal injection of urethane $(1.2 \mathrm{mg} / \mathrm{kg}$ body weight) and intubated in the trachea to keep the airway unimpeded. Following laparotomy, the superior mesenteric artery was occluded with an atraumatic microvascular clamp for $20 \mathrm{~min}$ of ischemia and then the clamp was removed for $60 \mathrm{~min}$ of reperfusion. ${ }^{42}$ Sham operation groups were subjected to laparotomy and mock manipulation of the artery without occlusion. All rats were placed on heating pads and rectal temperature monitored to prevent hypothermia during the surgical procedures. At the end of the experiments, rats were killed and tissue samples were collected for analysis.

\section{Neutrophil Depletion}

In a separate experiment, rats were rendered neutropenic by administration of polyclonal rabbit anti-PMN antibody (Accurate Chemical, USA) as previously described with slight modification. ${ }^{27}$ After receiving HPC for 20 days, rats were injected intraperitoneally with $0.6 \mathrm{ml}$ of anti-PMN immediately before the start of the last session of HPC for another $17 \mathrm{~h} .{ }^{27}$ The isotype control groups received normal rabbit serum, of which the antibody concentration was the 
same as to anti-PMN. These HPC rats administered antiPMN or isotype antibodies then underwent the surgical procedures for $\mathrm{I} / \mathrm{R}$ challenge.

\section{Analysis of Bacterial Counts in Intestines and Extraintestinal Organs}

Intestinal segments $(1 \mathrm{~cm}$ in length, $5 \mathrm{~cm}$ proximal to the ileocecal junction), liver and spleen were excised using aseptic techniques and weighed using an analytical balance accurate to $0.1 \mathrm{mg}$. The luminal content of intestinal segments was gently washed away with sterile PBS before weight measurement. Tissues were then homogenized and sonicated in sterile PBS at a concentration of $0.1 \mathrm{~g} / \mathrm{ml}$. The tissue homogenate (200 $\mu$ l per plate) was cultured at $37^{\circ} \mathrm{C}$ overnight on fresh blood agar and McConkey agar plates (Scientific Biotech, Taiwan) to examine the growth of total and $\mathrm{G}(-)$ bacteria, respectively. The bacterial colony-forming units (CFUs) were calculated and normalized per gram of tissue $(\mathrm{CFU} / \mathrm{g}){ }^{43,44}$

\section{Ussing Chamber Studies and Macromolecular Flux Assay}

Muscle-stripped intestinal tissues were opened along the mesenteric border and mounted in Ussing chambers (WPI Instruments, USA). The opening of the chamber $\left(2 \mathrm{~cm}^{2}\right)$ exposed the tissue to $10 \mathrm{ml}$ of circulating oxygenated Krebs buffer. The serosal buffer contained $10 \mathrm{mM} / \mathrm{l}$ of glucose that was osmotically balanced with $10 \mathrm{mM} / \mathrm{l}$ of mannitol in the mucosal buffer. A circulating water bath maintained the temperature of the buffer at $37^{\circ} \mathrm{C}$. The potential difference between the two compartments was clamped at $0 \mathrm{~V}$ using a voltage clamp amplifier, and the short-circuit current of the tissue was then determined. The tissue conductance $(G)$ was determined according to Ohm's law at 5-min intervals by the change in the Isc in response to a $1 \mathrm{mV}$ pulse for $1 \mathrm{~s} .{ }^{45,46}$

Intestinal permeability was determined by the level of mucosal-to-serosal flux of horseradish peroxidase (HRP type II, MW $44 \mathrm{kD}$; Sigma, USA). Tissues mounted in the Ussing chamber were allowed to equilibrate until the Isc stabilized before HRP was added to the mucosal buffer at a final concentration of $5 \times 10^{-5} \mathrm{M} / \mathrm{l}$. Samples $(320 \mu \mathrm{l})$ of serosal buffer were collected at $0,30,60$ and 90 min after addition of HRP, and were replaced with Krebs buffer/glucose. The concentration of HRP in serosal buffer was determined by a kinetic enzymatic assay, and HRP fluxes were calculated according to standard formulae and expressed as pmole $/ \mathrm{cm}^{2} / \mathrm{h}$, as previously described. ${ }^{45,46}$

\section{Magnetic Resonance Imaging (MRI)-Based Intestinal Permeability Assay}

To assess the intestinal permeability in vivo, Gadodiamide (Gd)-containing contrast solution (Omniscan; GE Healthcare, USA) was instilled into the lumen of a ligated intestinal $\operatorname{sac}(10 \mathrm{~cm})$ to a final concentration of $0.25 \mathrm{M}$ immediately after the release of the artery clamp in I/R rats, and the signal intensity of this reagent in the plasma was quantified as described previously. ${ }^{5,47}$ The intestinal sac was created $1 \mathrm{~cm}$ proximal to the cecum by thread ligature and a PE-10 tube was intubated to one end of the sac for instillation of Gd solution. In sham-operated animals, the Gd probe was injected into the intestinal sac after mock manipulation. To quantify the flux of Gd probe from gut lumen to systemic circulation, blood samples of $0.5 \mathrm{ml}$ were obtained from rats before $(t=0 \mathrm{~min})$ and 15,30 and $60 \mathrm{~min}$ after the Gd-probe was injected into the intestinal sac. A known concentration $(0.5 \mathrm{M})$ of $\mathrm{Gd}$ solution was serially diluted with neat plasma to prepare standard solutions for the calibration curve. Plasma and standard solution were subjected to MRI scan, with the imaging parameters $\mathrm{TR} / \mathrm{TE}=550 / 67.50 \mathrm{~ms}$, $\mathrm{FOV}=14 \times 0.5 \mathrm{~cm}^{2}$ and NEX $=4$. The plasma Gd concentration was calculated from the standard curve. ${ }^{5,47}$

\section{Neutrophil Respiratory Burst Activity}

Fresh heparinized blood was used for the measurement of neutrophil respiratory burst activity as previously described. ${ }^{48}$ A sample of whole blood $(20 \mu \mathrm{l})$ was diluted with $980 \mu \mathrm{l}$ of PBS. The cell suspension was loaded with $10 \mu \mathrm{l}$ of the fluorogenic substrate dihydrorhodamine (DHR) 123 (Molecular Probes, USA) to a final concentration of $1 \mu \mathrm{M}$ and incubated at $37^{\circ} \mathrm{C}$ for $5 \mathrm{~min}$. Subsequently, $1 \mu \mathrm{M}$ of f-Met-Leu-Phe (fMLP) (Sigma) was added to the cell suspension and incubated for $30 \mathrm{~min}$. Non-fluorescent DHR 123 could be oxidized to fluorescent rhodamine by hydrogen peroxide. The cell suspension was then placed on ice to stop
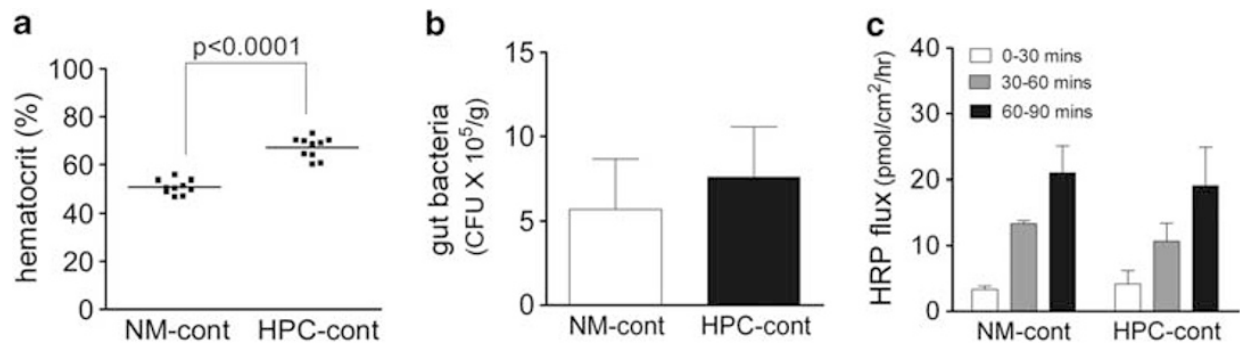

Figure 1 Enteric bacterial numbers and intestinal permeability were not modified by hypoxic preconditioning (HPC). The blood hematocrit levels (a), enteric bacterial numbers (b) and intestinal macromolecular flux rates (c) were determined in rats raised in normoxia (NM) or those exposed to HPC. The control (cont) rats in the two groups were killed before surgical procedures of mesenteric ischemia/reperfusion (I/R) or sham operation. Values were expressed as means \pm s.e.m. $N=10-12$ per group $(\mathbf{a}, \mathbf{b}) ; N=6$ per group (c). 
the reaction after the incubation period, washed once with PBS and centrifuged at $400 \times g$ for $3 \mathrm{~min}$. The pelleted cells were mixed with red blood cell lysis buffer $\left(150 \mathrm{mM} \mathrm{NH}_{4} \mathrm{Cl}\right.$ and $20 \mathrm{mM} \mathrm{NaHCO}$ in water) and incubated for 6 min on ice until the turbidity was lost and the solution became clear. The cells were washed, resuspended with $200 \mu \mathrm{l}$ of PBS and analyzed by FACS. For analysis, 5000 cells of each sample were acquired and the intensity of fluorescence (emission at $520 \mathrm{~nm}$ after $488 \mathrm{~nm}$ excitation) was detected. The amount of green fluorescence (rhodamine) in the cells is proportional to the extent of the hydrogen peroxide generated. The leukocytes of interest, that is, neutrophils, were readily identified by their typical side scatter and forward scatter patterns and gated for the analysis of fluorescence units. ${ }^{48}$

\section{Neutrophil Isolation}

Blood samples were collected and immediately put on ice for neutrophil isolation following protocols with slight mod- ification. ${ }^{49}$ A $4 \mathrm{ml}$ volume of Histopaque-1083 (Sigma) was placed at the bottom of a conical tube and the same volume of blood was carefully and slowly layered onto the gradient. The tube was centrifuged at $400 \times g$ for $45 \mathrm{~min}$ to separate the medium into three distinct phases. The upper two layers containing plasma, mononuclear cells and Histopaque were discarded, and the lower layer containing neutrophils and erythrocytes was collected. The lower layer was mixed with $2 \mathrm{ml}$ of a 6\% dextran solution (MW 500 000; Sigma) in $0.15 \mathrm{M} \mathrm{NaCl}$ and the total volume increased to $7 \mathrm{ml}$ with PBS. The tube was put on ice for $30 \mathrm{~min}$ and the supernatant was collected for centrifugation at $270 \times g$ for $10 \mathrm{~min}$ at $4{ }^{\circ} \mathrm{C}$. The contaminating erythrocytes in the pellet were lysed with $0.83 \%(\mathrm{w} / \mathrm{v}) \mathrm{NH}_{4} \mathrm{Cl}$ in water for $5 \mathrm{~min}$ and then the solution was centrifuged at $480 \times \mathrm{g}$ for $10 \mathrm{~min}$ at $4{ }^{\circ} \mathrm{C}$. The pelletcontaining neutrophils was washed with Hank's buffered saline solution (HBSS) at $270 \times g$ for $8 \mathrm{~min}$ at $4{ }^{\circ} \mathrm{C}$, resuspended in HBSS and the cell number determined using a
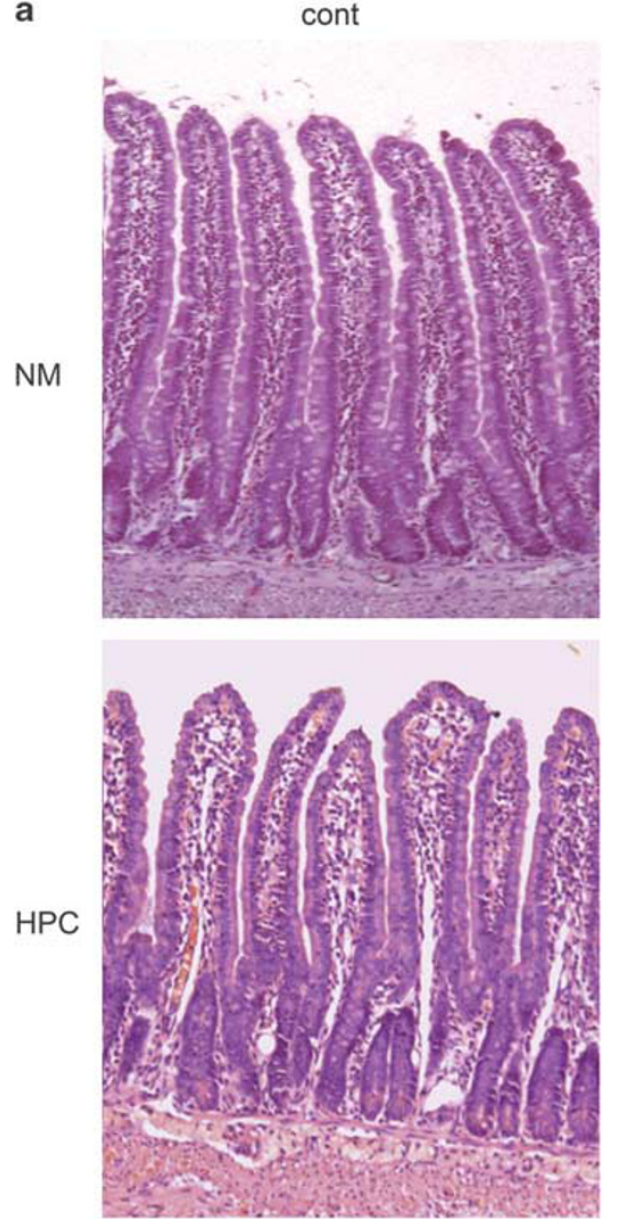

sham
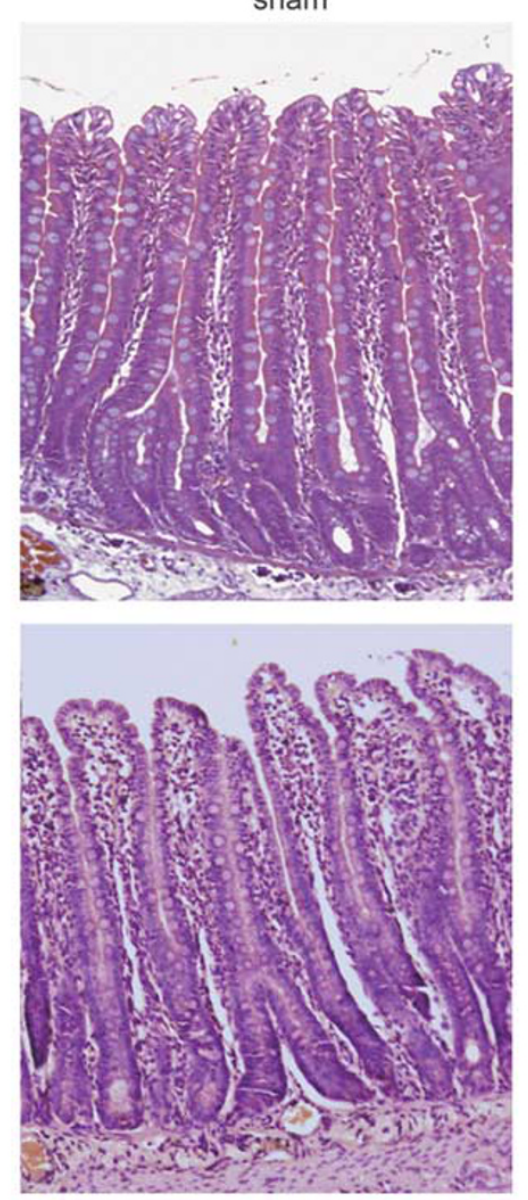

I/R
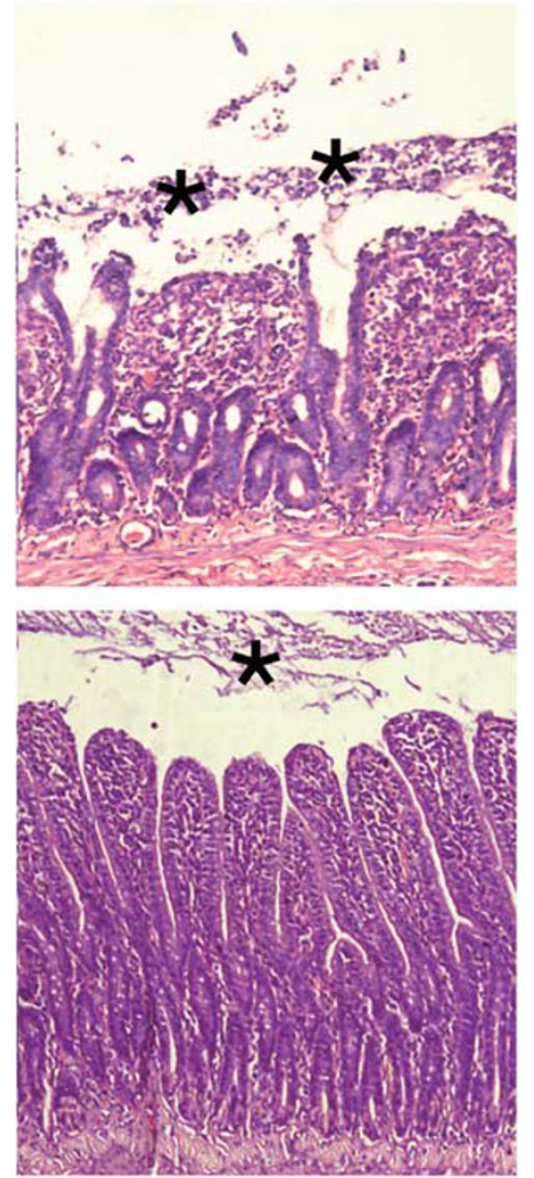

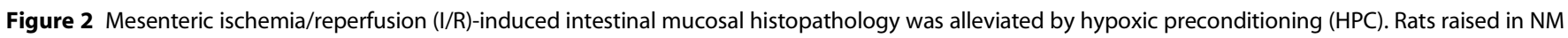
or HPC were killed directly as control (cont), or underwent surgical procedures of sham operation (sham) and mesenteric I/R. Intestinal sections in each group of rats were processed for H\&E staining (a), and immunostaining for PCNA (b). Representative images are shown (magnification $\times 100$ ). Normal intestinal histology with immunoreactivity to PCNA in crypts was seen in normoxia (NM)-cont, NM-sham, HPC-cont and HPC-sham rats. Severe villus blunting associated

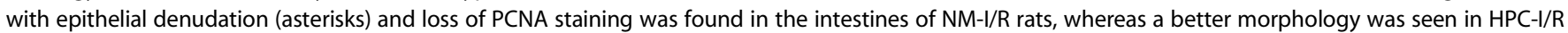
rats. The intestinal histopathological scores (c) were determined for each rat, and the values were expressed as means \pm s.e.m. $N=6$ per group. 

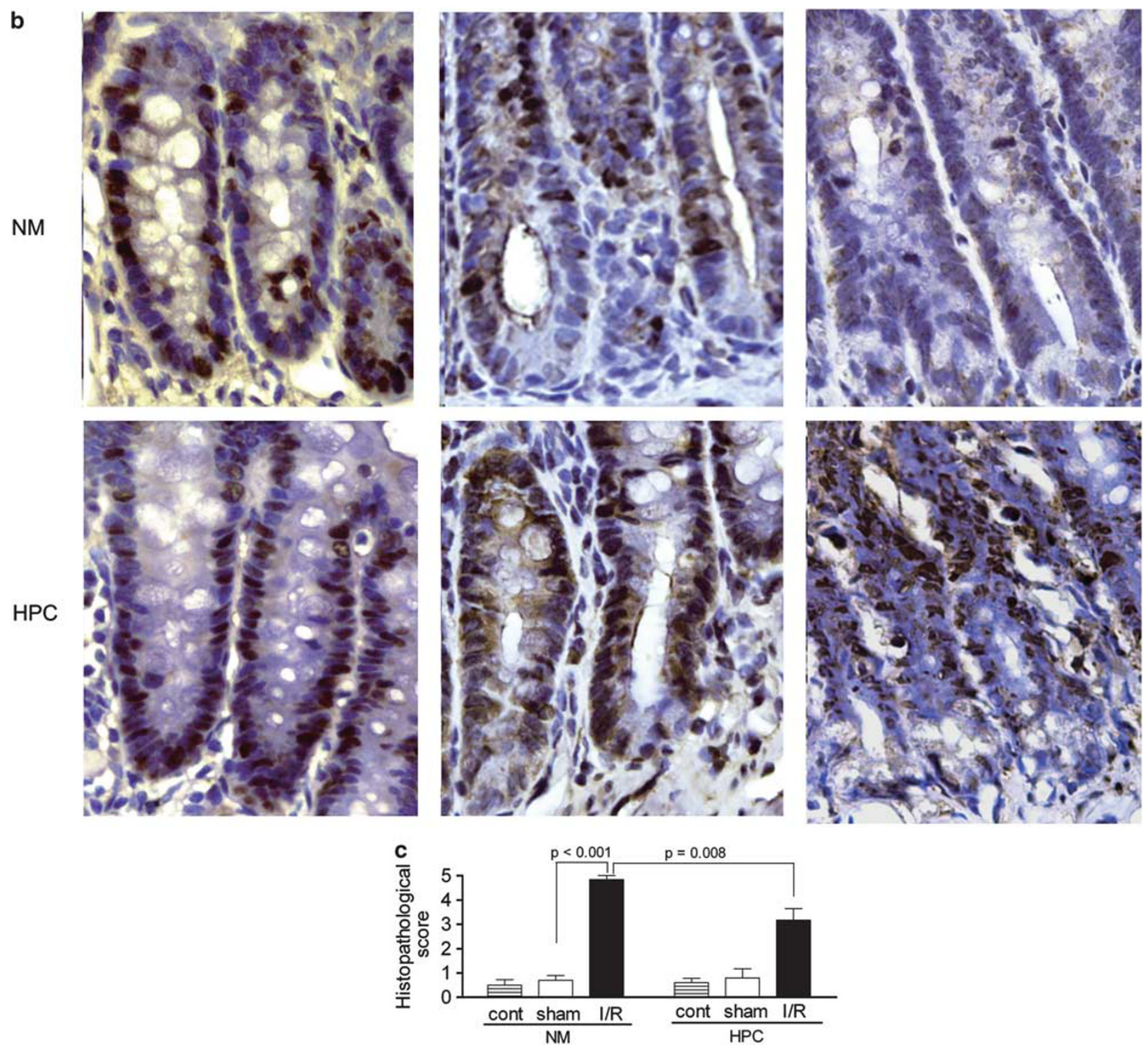

Figure 2 Continued.

a hemocytometer. The purity of neutrophils in cell preparations was determined to be $84.1 \pm 0.8 \%$.

\section{Bactericidal and Phagocytotic Activity of Neutrophils}

The bactericidal assay was performed as previously described with slight modification. ${ }^{50,51}$ Freshly isolated neutrophils $\left(10^{6}\right.$ cells) were incubated with $10^{7}$ CFUs of ampicillinresistant E. coli strain DH5 in HBSS (Invitrogen) in a 24-well plate for 15,30 and $60 \mathrm{~min}$ at $37^{\circ} \mathrm{C}$ with gentle shaking. Negative control samples contain bacteria or neutrohils alone. After various incubation times, extracellular bacteria were separated from neutrophils by centrifugation at $400 \times g$ for $3 \mathrm{~min}$ at $4{ }^{\circ} \mathrm{C}$. The supernatant containing $E$. coli was plated on Luria-bertani (LB) agar with $100 \mu \mathrm{g} / \mathrm{ml}$ ampicillin, and incubated for $24 \mathrm{~h}$ at $37^{\circ} \mathrm{C}$. The viable bacterial counts were determined per plate and the data presented as CFUs.

After removing the supernatant, neutrophil pellets were resuspended in HBSS with $300 \mu \mathrm{g} / \mathrm{ml}$ gentamicin for $1 \mathrm{~h}$ at $37^{\circ} \mathrm{C}$ to kill the adherent extracellular bacteria. To determine bacterial uptake by neutrophils, neutrophils were washed with cold PBS to remove gentamicin and lysed with $0.1 \%$ Triton X-100 for $20 \mathrm{~min}$ at $4{ }^{\circ} \mathrm{C}$ to release intracellular bacteria. The lysates were plated onto LB agar with $100 \mu \mathrm{g} / \mathrm{ml}$ ampicillin and incubated for $24 \mathrm{~h}$ at $37^{\circ} \mathrm{C}$. The numbers of phagocytosed bacteria was determined per plate and presented as CFUs. ${ }^{52}$

In a separate experiment, isolated neutrophils $\left(10^{6}\right.$ cells $)$ were preconditioned with $0.25 \mathrm{ml}$ of serum from HPC and $\mathrm{NM}$ rats for $60 \mathrm{~min}$ at $37^{\circ} \mathrm{C}$. After washing off the serum, 
Table 1 Villus height, crypt depth and C/V ratios of rat intestinal tissues

\begin{tabular}{|c|c|c|c|c|c|c|}
\hline & \multicolumn{3}{|c|}{ NM } & \multicolumn{3}{|c|}{ HPC } \\
\hline & Cont & Sham & $\mathrm{I} / \mathrm{R}$ & Cont & Sham & $\mathrm{I} / \mathrm{R}$ \\
\hline Crypt ( $\mu \mathrm{m})$ & $144.1 \pm 8.9$ & $128.8 \pm 7.3$ & $150.3 \pm 9.0$ & $121.0 \pm 5.9$ & $123.9 \pm 5.8$ & $135.8 \pm 9.8$ \\
\hline Villi $(\mu \mathrm{m})$ & $327.0 \pm 10.3$ & $316.7 \pm 15.1$ & $120.2 \pm 8.6^{*}$ & $288.1 \pm 8.8$ & $286.9 \pm 7.1$ & $217.7 \pm 13.1^{* * * *}$ \\
\hline
\end{tabular}

${ }^{\star} P<0.05$ vs respective sham rats.

${ }^{*} \mathrm{P}<0.05$ vs $\mathrm{NM}-\mathrm{I} / \mathrm{R}$ rats.

A shorter villus length and a higher $C / N$ ratio were demonstrated in NM-I/R rats compared with NM-sham rats. The villus length and $C / N$ ratio were partially recovered in HPC-1/R groups.

Values were expressed as means \pm s.e.m.

$N=6$ per group.

preconditioned neutrophils were incubated with $E$. coli for $30 \mathrm{~min}$ for bactericidal and phagocytotic assays as described.

\section{Lucigenin-Based Chemiluminescence (CL) Assay}

The production of superoxide in isolated neutrophils was assessed by a lucigenin-based assay. The cells $\left(10^{6}\right.$ neutrophils in $800 \mu \mathrm{l}$ of HBSS) were incubated at $37^{\circ} \mathrm{C}$ for $100 \mathrm{~s}$ followed by addition of $10 \mu \mathrm{M}$ lucigenin ( $100 \mu \mathrm{l}$ in volume) for $200 \mathrm{~s}$. After stimulation with $10 \mu \mathrm{M}$ fMLP or HBSS (100 $\mu \mathrm{l}$ in volume), cells were incubated for another $300 \mathrm{~s}$. The superoxide production was recorded by a CL analyzer (CLD-110; Tohoku Electronic Industrial, Japan) every $10 \mathrm{~s}$ for a total of $600 \mathrm{~s}$. The results were expressed in cumulative counts of area under curve after subtracting the baseline value without lucigenin and fMLP. ${ }^{49}$

\section{Statistical Analysis}

All data are presented as mean \pm s.e.m. All comparisons were made by one-way analysis of variance followed by StudentNewman-Keuls post-hoc test (Sigma Stat). A $P$-value $<0.05$ is considered significant.

Detailed information about measurement of hematocrit levels, differential leukocyte counts, histopathological scoring, neutrophil-specific esterase staining, immunohistochemical staining, immunofluorescent analysis, confocal microscopy, intestinal MPO activity and ELISA are provided in the Supplementary Text.

\section{RESULTS}

HPC Did Not Modulate Enteric Bacterial Numbers and Macromolecular Permeability in Rat Small Intestines

To ensure that the HPC test subjects were preconditioned in the chamber, the blood hematocrit levels that indicate the proportion of erythrocytes in volume were first examined. The hematocrit value in HPC-cont rats $(67.2 \pm 1.4 \%)$ was significantly higher than NM-cont rats $(51.0 \pm 0.9 \%)$ (Figure 1a). Intestinal bacterial numbers were comparable between HPCcont and NM-cont rats (Figure 1b). The bacterial counts in the liver and spleen in both groups of rats were negligible (data not shown). The transmural macromolecular flux rates of intestinal tissues in HPC-cont and NM-cont rats were comparable (Figure 1c). In addition, NM-cont and HPC-cont rats showed normal histological structure of the small intestine (Figure 2a and Table 1).

\section{Mesenteric I/R-Induced Intestinal Mucosal Injury and Barrier Dysfunction were Attenuated by HPC}

Rats exposed to NM and HPC were subjected to surgical procedures of mesenteric I/R or sham operation. Normal histological structure was seen in the small intestine of NM-sham and HPC-sham rats (Figure 2a). Severe mucosal damage, including villus blunting associated with epithelial denudation and lamina propria disintegration, was noted in $\mathrm{NM}-\mathrm{I} / \mathrm{R}$ rats (Figure 2a). In contrast to NM-I/R rats, longer villus structure with epithelial cell coverage was seen in HPC$\mathrm{I} / \mathrm{R}$ rats (Figure 2a). Moreover, PCNA-positive cells were found in the small intestinal crypts of NM-sham, HPC-sham and HPC-I/R rats; however, no staining was seen in NM-I/R rats (Figure $2 \mathrm{~b}$ ). The histopathological score was presented in Figure $2 c$. The villus length, crypt depth and $\mathrm{C} / \mathrm{V}$ ratio were similar in NM-sham and HPC-sham rats (Table 1). Shorter villus length and higher $\mathrm{C} / \mathrm{V}$ ratios were seen in NM-I/R rats than in NM-sham rats. The villus length and $\mathrm{C} / \mathrm{V}$ ratio were partially recovered in HPC-I/R groups (Table 1).

Increased transmural electrical conductance (Figure $3 \mathrm{a}$ ) and macromolecular flux (Figure $3 \mathrm{~b}$ ) were seen in the intestinal tissues in NM-I/R compared with NM-sham rats. These values in HPC-I/R rats were significantly lower than those of NM-I/R rats (Figures $3 \mathrm{a}$ and $\mathrm{b}$ ). The real-time change of gut permeability in vivo was also assessed by portal drainage of enterally administered Gd using MRI techniques ${ }^{47}$ (Supplementary Figure 1). The Gd concentration in plasma samples of NM-I/R groups was significantly higher than that of NM-sham rats as early as $15 \mathrm{~min}$ after reperfusion, a condition that persisted up to $60 \mathrm{~min}$ (Figure 3c). In contrast, decreased levels of plasma Gd were seen in HPC-I/R rats compared with NM-I/R rats (Figure 3c). 
a

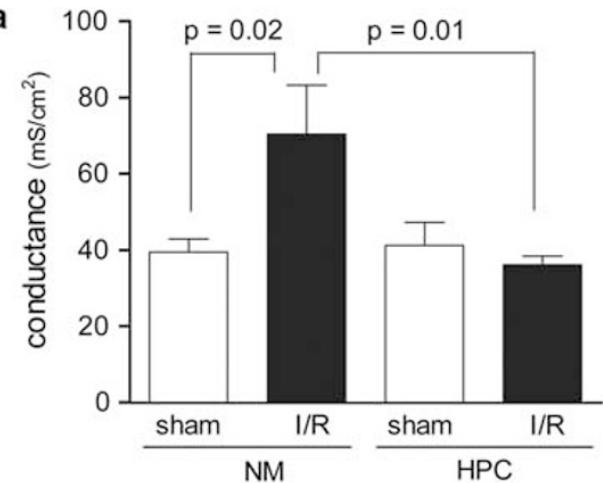

b
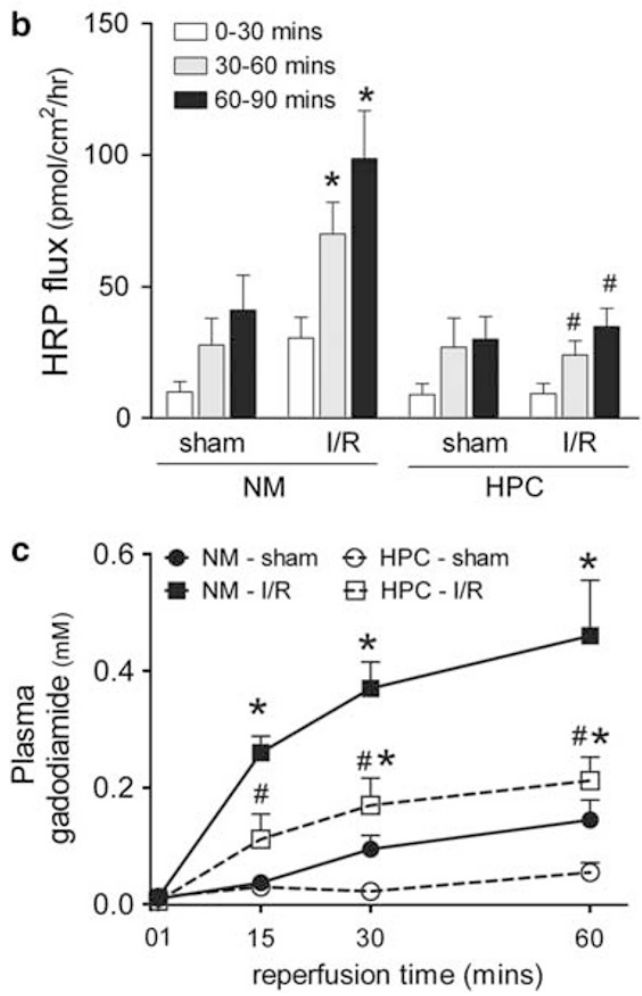

Figure 3 Mesenteric ischemia/reperfusion (I/R)-induced intestinal barrier dysfunction was attenuated by hypoxic preconditioning (HPC). Intestinal tissues of normoxia (NM) and HPC rats that underwent sham operation or mesenteric $\mathrm{I} / \mathrm{R}$ challenge were mounted on Ussing chambers for measurement of transmural electrical conductance (a) and horseradish peroxidase (HRP) fluxes (b). The rate of HPR flux was determined at different time points after luminal addition of the probe: 0 to 30, 30 to 60 , and 60 to $90 \mathrm{~min}$. Increased tissue conductance and HRP flux was seen in NM-I/R rats compared with NM-sham groups. These intestinal values in HPC-1/R rats were significantly lower than those of NM-l/R rats. Intestinal permeability changes during the reperfusion phase were also measured in vivo by using ligated loops administered with a contrast agent gadodiamide (Gd) for magnetic resonance imaging (MRI)-based assays (c). The luminal-to-blood passage of $\mathrm{Gd}$ was increased in NM-I/R rats compared with NM-sham groups. A significantly lower concentration of Gd was noted in plasma samples of HPC-I/R rats compared with that of NM-I/R rats. Values were expressed as means \pm s.e.m. ${ }^{\star} P<0.05$ vs respective sham group. ${ }^{\#} P<0.05$ vs NM-I/R rats. $N=8-10$ per group $(\mathbf{a}, \mathbf{b}) ; N=4-5$ per group (c).

The changes in intestinal permeability correlated well with the extent of BT. The total bacterial CFUs in the liver and spleen tissues of NM-I/R rats were significantly higher than those of NM-sham rats (Figures $4 \mathrm{a}$ and $\mathrm{b}$ ). No differences in the liver and spleen total bacterial CFUs were noted between HPC-I/R and HPC-sham rats (Figures $4 \mathrm{a}$ and $\mathrm{b}$ ). Similar results were seen in Gram-negative bacterial counts in the liver and spleen (Figures $4 \mathrm{c}$ and $\mathrm{d}$ ).

\section{Augmentation of Neutrophil Chemotaxis and MPO Activity in the Gut Mucosa in HPC-I/R Rats}

It was speculated that neutrophils in the gut mucosa may also have important roles in curbing enteric BT. Therefore, the respiratory burst activity and chemotactic gradient for neutrophils in intestinal tissues were assessed. $\mathrm{I} / \mathrm{R}$ challenge elevated the intestinal MPO activity in both NM and HPC rats, of which the values in HPC-I/R rats $(2.41 \pm 0.38$ units/ $\mathrm{mg}$ ) were statistically higher than that of $\mathrm{NM}-\mathrm{I} / \mathrm{R}$ rats $(0.78 \pm 0.12$ units/mg; Figure $5 \mathrm{a})$. Moreover, $\mathrm{I} / \mathrm{R}$ challenge also raised the intestinal CINC-1 levels in both NM and HPC rats (Figure 5b). The intestinal CINC-1 concentration in HPC-I/R rats was significantly higher than NM-I/R rats (Figure 5b). The intestinal levels of rat CINC-3 did not differ between NM-sham and NM-I/R rats, yet the chemokine in HPC-I/R rats were higher than HPC-sham rats (Figure $5 \mathrm{c}$ ). Elevated plasma concentrations of CINC-1 were found in HPC-I/R rats compared with HPC-sham rats, while the levels of plasma CINC-1 in NM-sham and NM-I/R rats were not significantly different (Figure 5d).

To further evaluate the extent of neutrophil infiltration into the gut, the location and morphology of neutrophils in mucosal tissues were examined. Rounded neutrophils were seen mostly near the base of intestinal crypts with some in the villus region in NM-sham rats and NM-I/R rats (Figure 6). In HPC rats, the morphology and the spatial arrangement of neutrophils were altered drastically. The intestinal neutrophils had an elongated appearance, and the cells were aligned sequentially along the axis of the blood capillaries in the villus core in HPC-sham and HPC-I/R rats (Figure 6).

\section{HPC Alone Increased the Numbers, Respiratory Burst Activity and Bacterial-Killing Effects of Blood Neutrophils}

The numbers and the respiratory burst activity of blood neutrophils were investigated in rats before surgical procedures. The percentage of neutrophils in total leukocytes $(19.18 \pm 1.96 \%$ vs $15.80 \pm 1.20 \%, P<0.05)$ and neutrophil numbers $\left(2.15 \pm 0.47\right.$ vs $\left.0.99 \pm 0.1\left(10^{3} / \mathrm{mm}^{3}\right), P<0.05\right)$ were higher in rats of the HPC-cont group than in the NM-cont group. The respiratory burst activity in blood neutrophils was examined after stimulation with bacterial fMLP by a dirhodamine conversion test. The neutrophil population in whole blood cells was first gated based on their size and granularity in the dot plot image for analysis (Figure 7a). For unstimulated neutrophils incubated in PBS, the fluorescent intensity of HPC-cont rats was markedly higher than that of NM-cont rats, indicating that HPC alone may activate neutrophil hydrogen peroxide production (Figure 7b). 

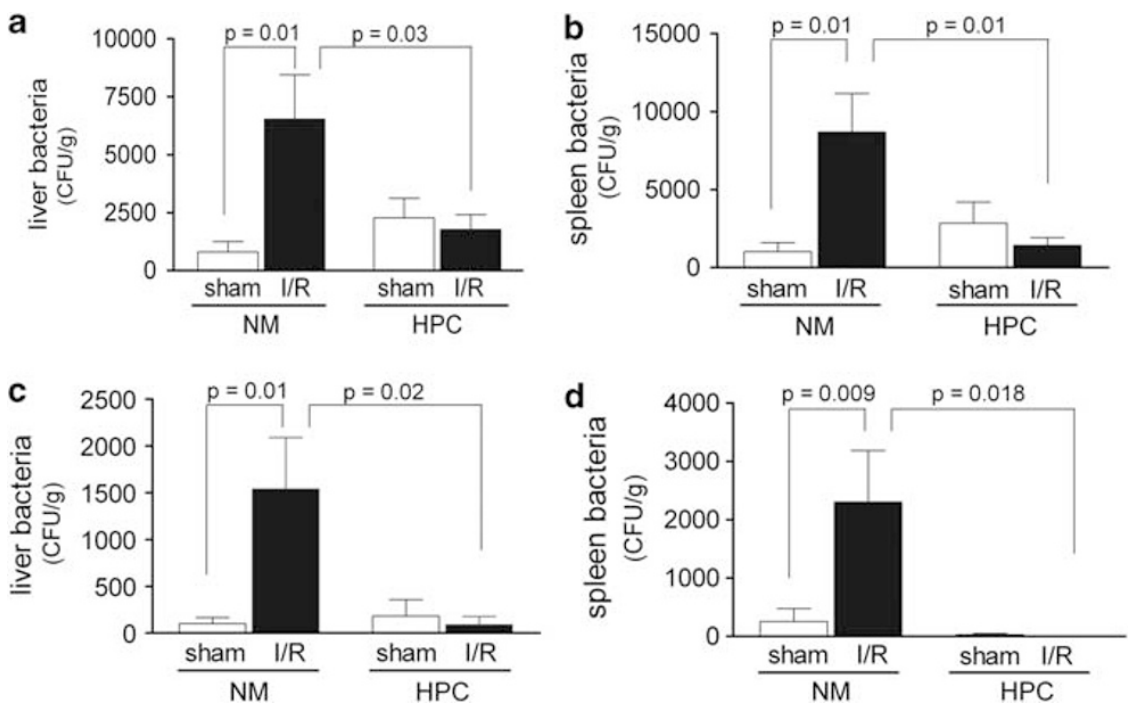

Figure 4 The increase in bacterial translocation after ischemia/reperfusion (I/R) challenge was abolished by hypoxic preconditioning (HPC). Homogenized liver (a, $\mathbf{c})$ and spleen (b, d) tissues in normoxia (NM) and HPC rats subjected to sham operation (sham) or mesenteric I/R challenge were cultured on fresh blood agar plates $(\mathbf{a}, \mathbf{b})$ or MacConkey agar plates $(\mathbf{c}, \mathbf{d})$. The bacterial colony forming units (CFUs) were calculated and normalized to tissue weight. Values were expressed as means \pm s.e.m. $N=9-12$ per group.
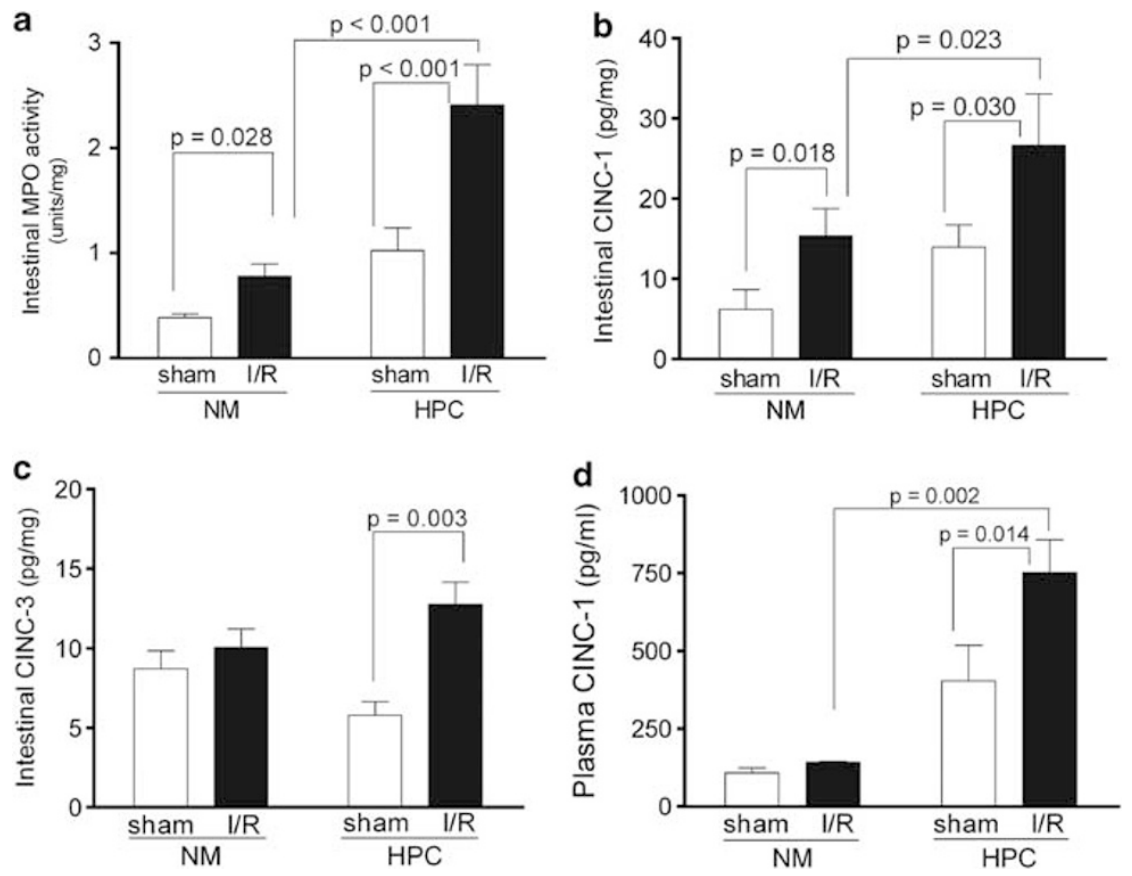

Figure 5 Enhanced levels of intestinal myeloperoxidase (MPO) activity and neutrophil chemoattractants were found in hypoxic preconditioning (HPC)ischemia/reperfusion (I/R) rats compared with normoxia (NM)-I/R rats. Intestinal levels of MPO activity (a), cytokine-induced neutrophil chemoattractant (CINC)-1 (b), CINC-3 (c), as well as plasma CINC-1 concentration (d) were determined in NM and HPC rats subjected to sham operation (sham) or mesenteric I/R. Values were expressed as means \pm s.e.m. $N=6$ per group.

The fluorescent intensity of neutrophils was further elevated after stimulation with exogenous fMLP compared with those incubated in PBS in both NM-cont and HPC-cont groups (Figure 7b). The fluorescent intensity of fMLP-stimulated neutrophils was higher in HPC-cont groups than in NM-cont groups (Figure $7 b$ ).
The activation of NADPH oxidase in blood neutrophils that catalyze superoxide production was examined using a lucigenin-enhanced CL assay. The baseline CL units of neutrophils of HPC-cont rats were higher than those of NM-cont rats (Figure 7c), suggesting that HPC alone triggers superoxide production in neutrophils. After stimulating with 

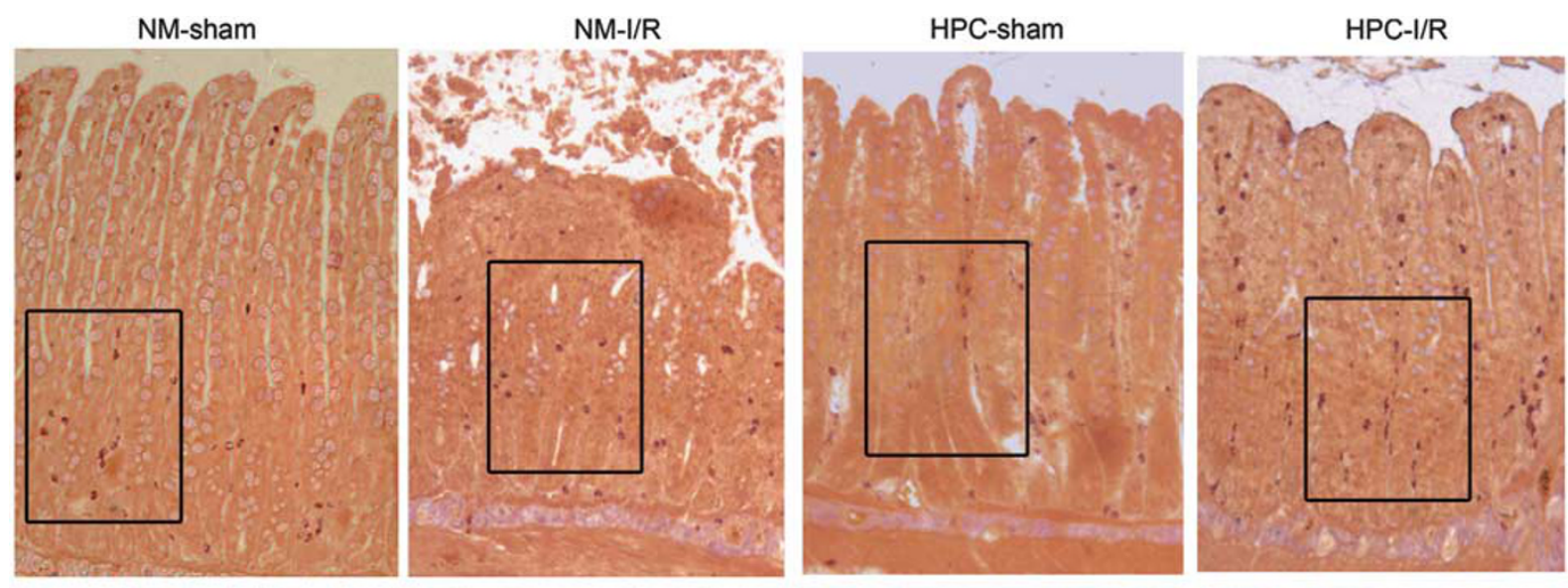

$100 X$
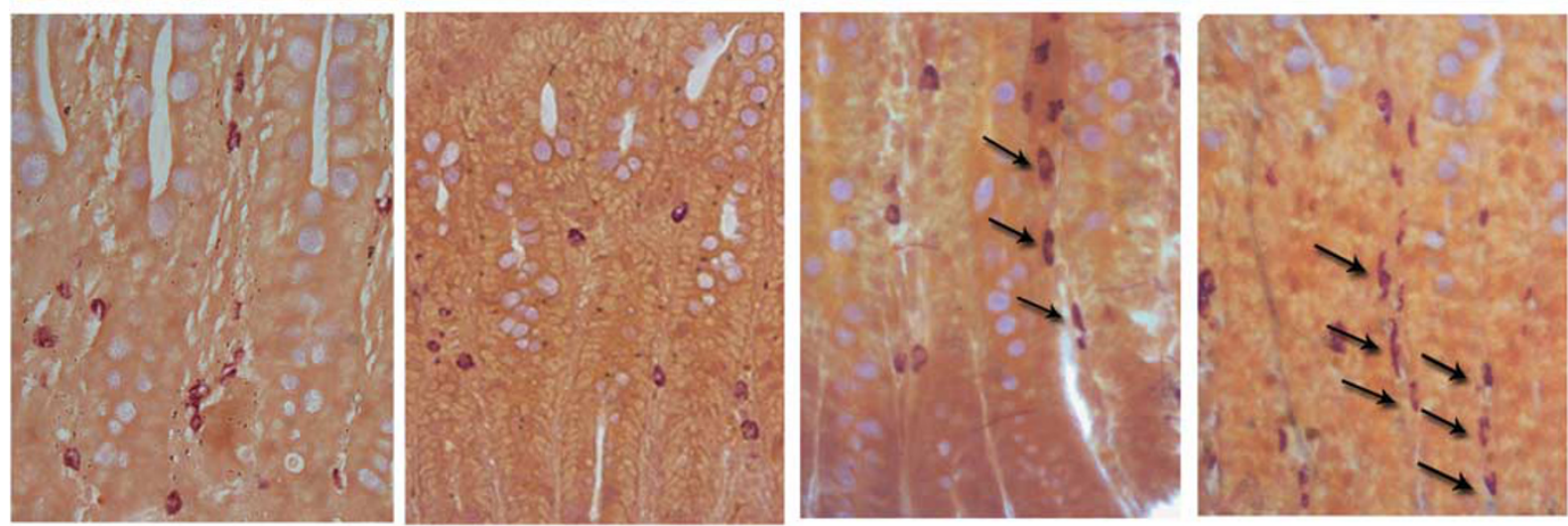

$400 X$

Figure 6 Altered location and morphology of neutrophils in intestinal tissues of hypoxic preconditioning (HPC) rats. Representative images show neutrophils in rat intestinal tissues. Magnification $\times 100$ (top panels); $\times 400$ (bottom panels). The insets in the top panels were enlarged to show the morphology of neutrophils. Rounded neutrophils were seen mostly near the base of intestinal crypts and some in the villus region in NM-sham and normoxia (NM)-ischemia/reperfusion (I/R) rats. The intestinal neutrophils (arrows) appeared elongated and the cells aligned sequentially along the axis of the blood capillaries in the villus core in HPC-sham and HPC-I/R rats. $N=4-5$ per group.

exogenous fMLP, the CL units and the area under the curve were higher for neutrophils isolated from HPC-cont rats than from NM-cont rats (Figures $7 \mathrm{c}$ and $\mathrm{d}$ ). The cytosolic NADPH oxidase subunits are known to migrate to the membrane to form a complex in response to priming. In NM-cont rats, p $47^{\text {phox }}$ (Figure 7e) and 67 $^{\text {phox }}$ (Figure 7f) were located in the cytosol of neutrophils, and did not colocalize with F-actin in superimposed images. In contrast, $\mathrm{p} 47^{\text {phox }}$ and $\mathrm{p} 67^{\text {phox }}$ staining was colocalized with F-actin in neutrophils of HPCcont rats (Figures $7 \mathrm{e}$ and $\mathrm{f}$ ).

To assess the bactericidal and phagocytotic activity, neutrophils from NM-cont and HPC-cont rats were incubated with $E$. coli at a 1:10 ratio for various time points in vitro, followed by bacterial harvesting and culturing on agar plates. The viable bacterial counts in the cell media of HPC-cont groups were lower than NM-cont groups after 30 and $60 \mathrm{~min}$ of co-incubation (Figure 8a). Moreover, the phagocytotic activity of neutrophils was significantly higher in HPC-cont groups compared with NM-cont groups at all time points (Figure 8b). No bacterial growth was found in isolated neutrophils of NM-cont and HPC-cont rats without the addition of exogenous E. coli (data not shown). To test if the priming effect may be carried over to naïve cells, isolated control neutrophils were incubated with serum from HPC-cont and NM-cont rats before the bactericidal assay. Our results have shown that neutrophils preconditioned with HPC serum showed higher bactericidal effects than those with NM serum (Figure 8c). The phagocytosed bacteria amount was slightly increased in neutrophils preconditioned with HPC serum compared with NM serum, albeit without statistical significance (Figure 8d).

\section{Neutrophil Depletion Reduced the Protective Effect of HPC Against I/R-Induced Intestinal Injury}

To investigate whether neutrophils were involved in the protective mechanism, rats exposed to HPC were rendered neutropenic by administration of anti-PMN before I/R challenge. The blood neutrophil counts in rats given antiPMN were significantly lower than those given isotype controls $\left(0.12 \pm 0.03\right.$ vs $\left.1.92 \pm 0.40\left(10^{3} / \mathrm{mm}^{3}\right), P<0.05\right)$, validating the depletion of circulating neutrophils. HPC rats that were pre-treated with anti-PMN showed a lower level of intestinal MPO activity on $\mathrm{I} / \mathrm{R}$ challenge compared with those with isotype antibodies (Figure 9a). The decrease in 
a

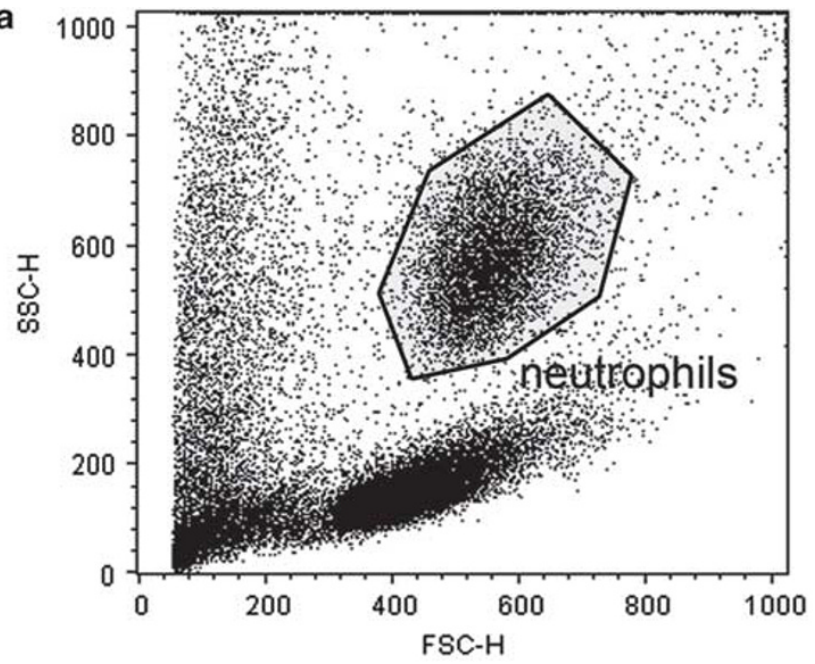

C

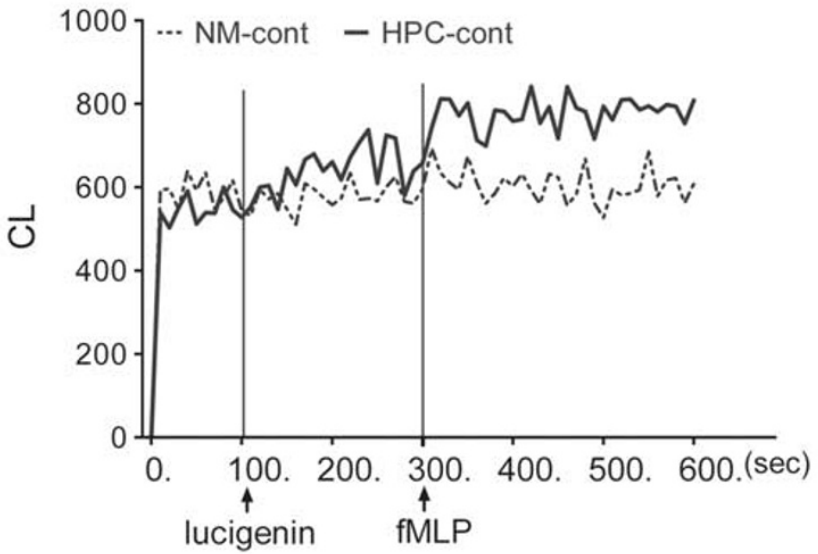

e

NM-
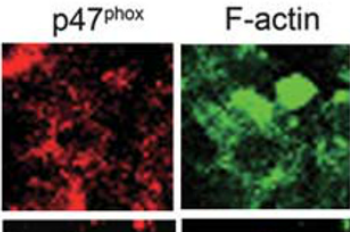

HPC-

cont
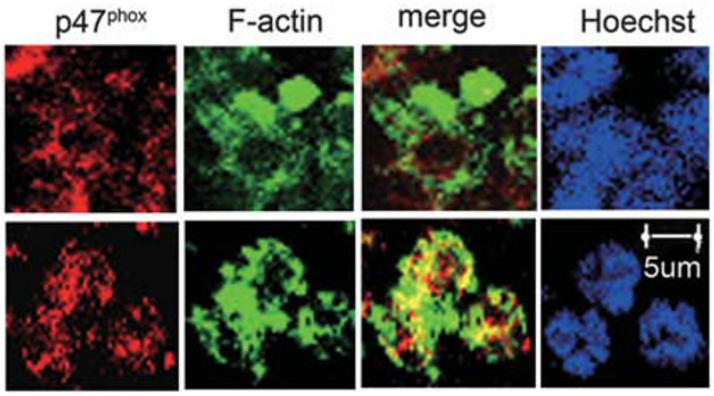

b
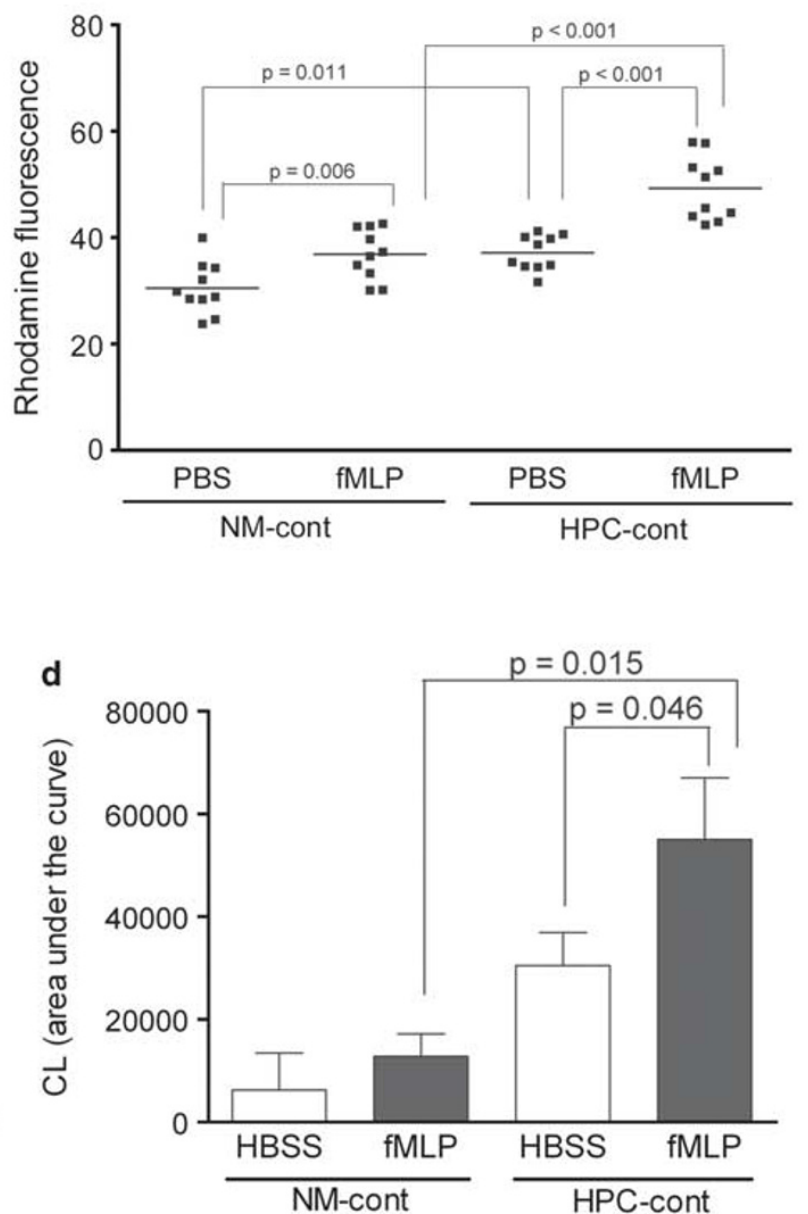

Figure 7 Hypoxic preconditioning (HPC) alone increased the respiratory burst activity of blood neutrophils. (a) A representative flow cytometric dot plot of forward scatter (FSC) vs side scatter (SSC) of a whole blood specimen without erythrocytes. Populations of neutrophilic granulocytes were differentiated by their characteristic size and granularity, and were gated for analysis of rhodamine conversion. (b) The fluorescent intensity of rhodamine in both normoxia (NM)-cont and HPC-cont groups was elevated after stimulation with exogenous f-Met-Leu-Phe (fMLP) compared with incubation with PBS, of which the values in HPC-cont groups were statistically higher than those in NM-cont groups. (c) A representative profile of lucigenin-enhanced chemiluminescence $(C L)$ units produced by isolated neutrophils before and after stimulation with fMLP. The baseline CL units (100-300 s) of neutrophils of HPC-cont rats were higher than those of NM-cont rats. After stimulating with exogenous fMLP (300-600 s), the CL units were higher for neutrophils isolated from HPC-cont rats than NM-cont rats. (d) The integrated area under the curve of lucigenin-enhanced CL generated from neutrophils was quantified. Neutrophils of HPC-cont rats stimulated with fMLP showed increased area under the curve compared with the unstimulated cells incubated in Hank's buffered saline solution (HBSS). Moreover, the area under the curve after fMLP stimulation in neutrophils of HPC-cont rats was higher than NM-cont rats. (e, $\mathbf{f})$ The distribution of nicotinamide adenine dinucleotide phosphate (NADPH) oxidase subunits ( $\mathrm{p} 47^{\text {phox }}$ or p67 ${ }^{\text {phox }}$, both in red color) and F-actin (green color) were examined in isolated blood neutrophils. Colocalization of NADPH oxidase subunits and F-actin (yellow color in superimposed images) were observed in neutrophils of HPC-cont rats but not NM-cont rats. Cell nuclei were stained blue with Hoechst dye. Magnification $\times 400$. Values were expressed as means \pm s.e.m. $N=10$ per group (a, b); $N=6$ per group (c, d); $N=3-4$ per group (e, $\mathbf{f})$. 

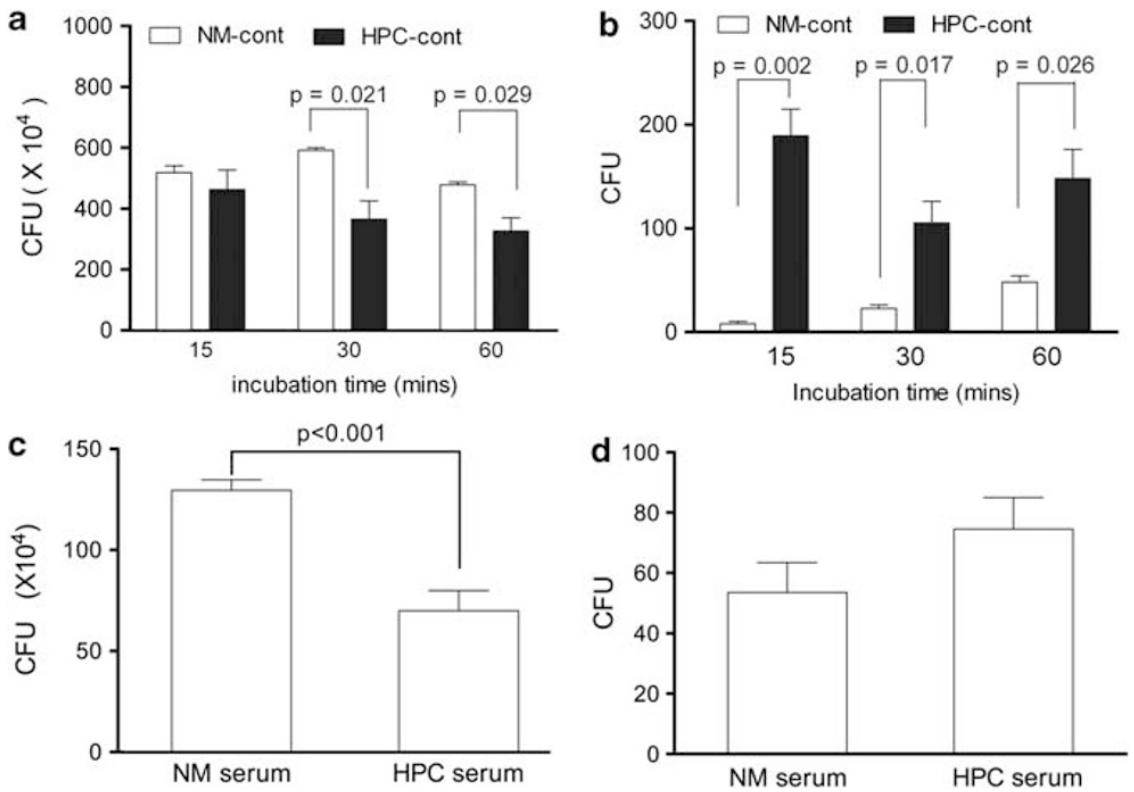

Figure 8 Increased bactericidal and phagocytotic activity of blood neutrophils following hypoxic preconditioning (HPC). Isolated neutrophils from normoxia (NM)-cont and HPC-cont rats were co-incubated with E. coli at a 1:10 ratio for various time points in vitro. (a) The viable bacterial counts in the cell media of HPCcont groups were lower than NM-cont groups after 30 and $60 \mathrm{~min}$ of co-incubation. (b) The phagocytosed bacterial amounts in neutrophils were determined by a gentamicin-killing assay. The phagocytotic activity of neutrophils was significantly higher in HPC-cont groups compared with NM-cont groups at all time points. (c) Isolated control neutrophils were incubated with serum from HPC-cont and NM-cont rats before the bactericidal assay. Neutrophils preconditioned with HPC serum showed higher bactericidal effects than those with NM serum. (d) The phagocytosed bacterial counts in neutrophils preconditioned with HPC serum was slightly increased compared with NM serum, albeit without statistical significance. $N=4$ per group (a, b); $N=6$ per group (c, d).

blood neutrophil numbers and intestinal MPO activity correlated the worsened mucosal histopathology in rats given anti-PMN, in comparison with those administered isotype antibodies (Figure 9b). The increased values of intestinal tissue conductance (Figure 9c) and HRP flux (Figure 9d) are accompanied by higher counts of liver bacterial CFUs (Figure 9e) in HPC-I/R rats given anti-PMN compared with those given isotype antibody. The intestinal levels of CINC-1 and CINC-3 were comparable between those given anti-PMN and isotype antibody (data not shown). Additional studies in $\mathrm{NM}-\mathrm{I} / \mathrm{R}$ rats have shown comparable levels of intestinal histopathology and tissue conductance in groups administered anti-PMN and isotype antibodies (Supplementary Figure 2).

\section{DISCUSSION}

Neutrophils have been incriminated in the pathogenesis of ischemic injury in various organs. ${ }^{12-14,53}$ However, the role of neutrophils in the intestinal tract, an organ full of bacteria, has been debatable. This study provides the first evidence that neutrophil priming and activation by HPC protects the ischemic intestine against barrier dysfunction. We demonstrated that HPC reduced extraintestinal bacterial counts, and alleviated the mucosal histopathology and epithelial permeability rise normally seen on mesenteric $\mathrm{I} / \mathrm{R}$; moreover, the protective effects of HPC may be reversed by neutrophil depletion. Increased neutrophil priming and activation prevents enteric bacterial intrusion through multiple pathways, including direct antimicrobial activity and promotion of epithelial barrier integrity.

Our previous studies demonstrated abnormal BT and increased epithelial permeability in mesenteric $\mathrm{I} / \mathrm{R}$ rats. ${ }^{5,47}$ Here, we showed that rats preconditioned to a hypoxic environment displayed a significant reduction in bacterial counts in extraintestinal organs, associated with decreases in transepithelial macromolecular flux and mucosal histopathology on $\mathrm{I} / \mathrm{R}$ challenge. The attenuation of BT may be attributed to higher barrier integrity and/or stronger antimicrobial effects of phagocytes. We demonstrated that the levels of neutrophil chemoattractants (CINC-1 and -3) and MPO activity in the gut mucosa of HPC-I/R rats were significantly higher than those of NM-I/R rats. In contrast to the rounded intestinal neutrophils in normoxic rats, elongated appearance and villus core alignment are typical features of neutrophils in rat intestines exposed to HPC. The altered morphology and distribution of intestinal neutrophils are consistent with the changes in chemokine levels, indicating that HPC increases neutrophil infiltration to gut tissues. These findings suggest a correlation between the HPC protective effect and an elevation of neutrophil infiltration and activation in gut mucosa.

The numbers and the priming status of blood neutrophils were next verified in rats following preconditioning. In comparison with rats kept in NM, higher numbers, and increased superoxide production, bactericidal and phagocytotic activities of blood neutrophils were found in HPC rats. 
a

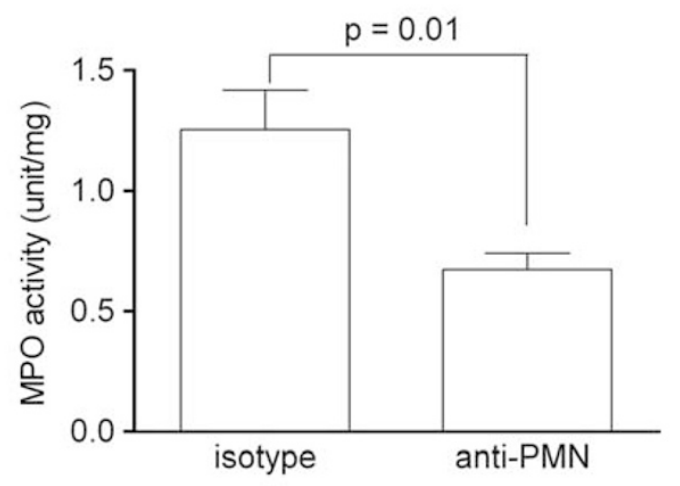

b

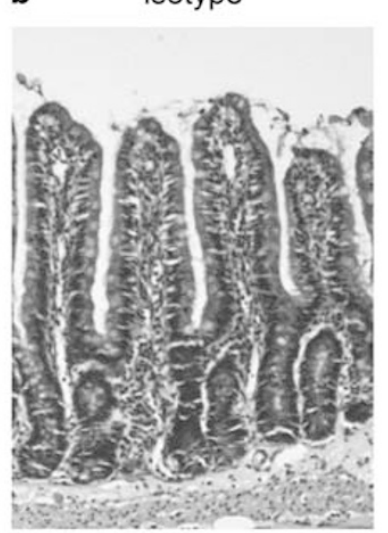

anti-PMN

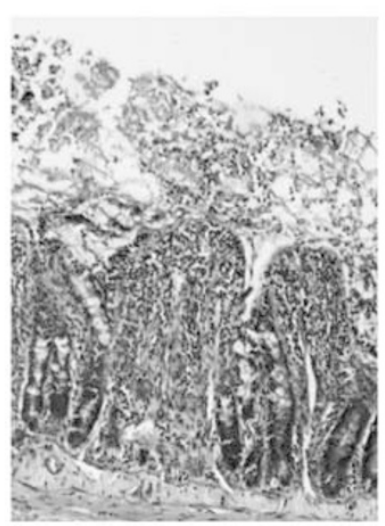

C

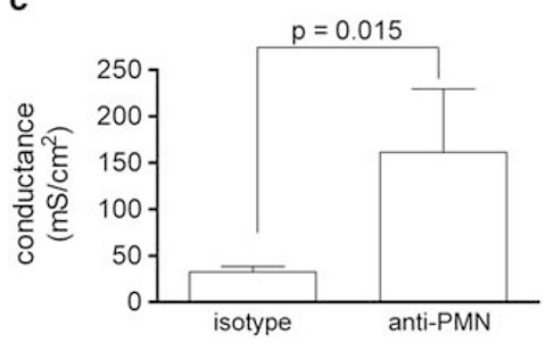

d

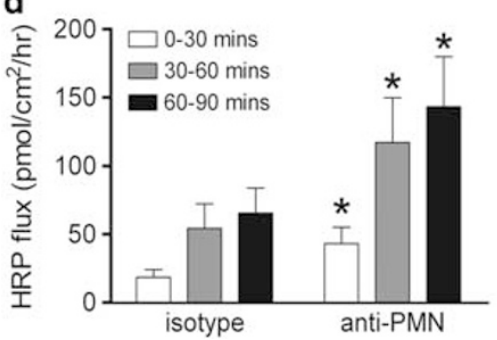

e

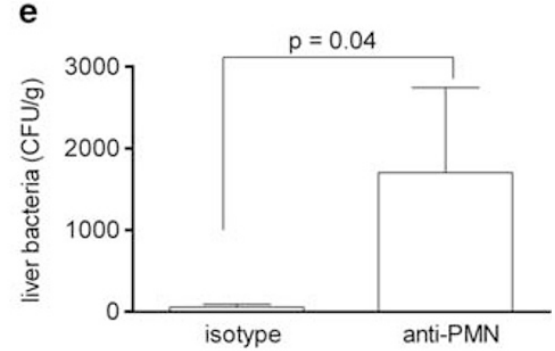

Figure 9 Depletion of blood neutrophils blocked the hypoxic preconditioning (HPC) protection against ischemia/reperfusion (I/R) injury. Rats exposed to HPC were administered anti-PMN or isotype antibodies, and then subjected to mesenteric $\mathrm{I} / \mathrm{R}$ challenge. Depletion of blood neutrophils was confirmed in rats administered anti-PMN compared with those given isotype antibodies $\left(0.12 \pm 0.03\right.$ vs $\left.1.92 \pm 0.40\left(10^{3} / \mathrm{mm}^{3}\right), P<0.05\right)$. (a) Decreased intestinal myeloperoxidase (MPO) activity was noted in rats treated with anti-PMN compared with those given isotype antibodies. (b) The intestinal mucosal structure in HPC-I/R rats treated with anti-PMN was worse than those with isotype antibodies (magnification $\times 100)$. (c) The intestinal tissue conductance was higher in rats administered anti-PMN compared with isotype antibodies. (d) Increased horseradish peroxidase (HRP) flux was seen in intestines of rats administered anti-PMN compared with isotype antibodies. ${ }^{*} P<0.05$ vs isotype. (e) Increased liver bacterial counts were seen in the anti-PMN groups compared with isotype groups. Values were expressed as means \pm s.e.m. $N=8$ per group.

The priming effect may be carried over to naïve neutrophils by preconditioning with HPC serum, suggesting that soluble factors are partly responsible for neutrophil priming. Taken together, these findings indicate that HPC may prime neutrophils for higher respiratory burst, stronger phagocytotic activity as well as faster infiltration, resulting in more efficient bacterial killing in target tissues. A number of substances are known to prime neutrophils, including proinflammatory cytokines (eg, IL- 8 and TNF $\alpha$ ) and bacterial products (eg, LPS and fMLP). ${ }^{10}$ Whether the presence of circulating bacterial products is also involved in the mechanism of neutrophil priming by HPC warrants further investigation.

In an organ full of commensal bacteria such as the intestine, neutrophil activation in the mucosa may be beneficial in limiting microbial dissemination. Based on this hypothesis, we examined whether neutrophil depletion may block the HPC protection against BT in I/R injury. In comparison with those given isotype control antibody, the administration of anti-PMN led to a $93.75 \%$ reduction in blood neutrophil numbers that correlated with higher extraintestinal bacterial counts, indicating that neutrophils are involved in the mechanism of microbial clearance exerted by HPC. It is worth noting that neutropenia inhibited the HPC protective effect on gut permeability and mucosal histopathology in which severe epithelial denudation and villus deformation were present in HPC-I/R rats. These findings suggest that in addition to their bacterial-killing activity, neutrophils may also contribute to the process of epithelial restitution and maintenance of mucosal barrier integrity on ischemic challenge. Therefore, in contrast to the common belief that neutrophil activation is a cause for histopathology and barrier damage in ischemic intestines, ${ }^{25,26,54}$ our findings suggest that neutrophils may be involved in protective mechanisms conferred by HPC to maintain gut barrier integrity. Previous studies of chemically induced colitis in rats revealed that depletion or adhesion blockade of neutrophils aggravated the intestinal histopathology, and promotion of bone marrow-derived granulocyte differentiation facilitated the mucosal repair processes. ${ }^{28,55,56}$ One report indicates that neutrophil-derived IL-1 $\beta$ is involved in promoting epithelial restitution and mucosal wound healing after ischemic challenge via a cyclooxygenase-2-dependent mechanism. ${ }^{57}$ Previous studies showed that adaptive hypoxia protects the intestinal epithelial barrier integrity via transcriptional regulation of hypoxiainducible factor $1 .^{22-24}$ Further investigation of the molecular 
mechanism of neutrophil-dependent protection of epithelial barrier is currently under progress.

In conclusion, neutrophil priming by HPC protects against mucosal barrier disruption and BT caused by mesenteric I/R. These results suggest caution in the use of anti-leukocyte therapy for treating intestinal ischemia. Our findings support HPC-based interventions for the correction of bacterial influx and septic complications in intestinal I/R injury.

Supplementary Information accompanies the paper on the Laboratory Investigation website (http://www.laboratoryinvestigation.org)

\section{ACKNOWLEDGEMENTS}

We thank the financial supports from National Science Council and the technical assistance in the first and third research core laboratories in NTUCM. This study was supported by Grants from the National Science Council, Taiwan, ROC, (NSC99-2320-B-002-024-MY3 and NSC99-2314-B-002085-MY2).

Author contributions: Guarantor of integrity of entire study, LCY; study concepts and design: LCY and CFC; data acquisition: YZL, CCW, YZH and CYY; data analysis/interpretation: YZL, TCL and LCY; statistical analysis: YZL; material and technical support: CYY; obtained funding: LCY and TCL; paper drafting or revision for important intellectual content, literature research, paper editing and paper final version approval: all authors.

\section{DISCLOSURE/CONFLICT OF INTEREST}

The authors declare no conflict of interest.

1. Mallick IH, Yang W, Winslet MC, et al. Ischemia-reperfusion injury of the intestine and protective strategies against injury. Dig Dis Sci 2004; 49:1359-1377.

2. Yasuhara H. Acute mesenteric ischemia: the challenge of gastroenterology. Surg Today 2005;35:185-195.

3. Colgan SP, Taylor CT. Hypoxia: an alarm signal during intestinal inflammation. Nat Rev Gastroenterol Hepatol 2010;7:281-287.

4. Cerqueira NF, Hussni CA, Yoshida WB. Pathophysiology of mesenteric ischemia/reperfusion: a review. Acta Cir Bras 2005;20:336-343.

5. Huang CY, Hsiao JK, Lu YZ, et al. Anti-apoptotic PI3K/Akt signaling by sodium/glucose transporter 1 reduces epithelial barrier damage and bacterial translocation in intestinal ischemia. Lab Invest 2010;91: 294-309.

6. Ley RE, Peterson DA, Gordon Jl. Ecological and evolutionary forces shaping microbial diversity in the human intestine. Cell 2006;124: 837-848.

7. O'Hara AM, Shanahan F. The gut flora as a forgotten organ. EMBO Rep 2006;7:688-693.

8. Souza DG, Vieira AT, Soares AC, et al. The essential role of the intestinal microbiota in facilitating acute inflammatory responses. J Immunol 2004;173:4137-4146.

9. Klebanoff SJ. Myeloperoxidase: friend and foe. J Leukoc Biol 2005;77:598-625.

10. Sheppard FR, Kelher MR, Moore EE, et al. Structural organization of the neutrophil NADPH oxidase: phosphorylation and translocation during priming and activation. J Leukoc Biol 2005;78:1025-1042.

11. Chin AC, Fournier B, Peatman EJ, et al. CD47 and TLR-2 crosstalk regulates neutrophil transmigration. J Immunol 2009;183: 5957-5963.

12. Matsumoto T, Ikeda K, Mukaida N, et al. Prevention of cerebral edema and infarct in cerebral reperfusion injury by an antibody to interleukin8. Lab Invest 1997;77:119-125.

13. Singbartl K, Ley K. Protection from ischemia-reperfusion induced severe acute renal failure by blocking E-selectin. Crit Care Med 2000;28:2507-2514.

14. Kin $H$, Wang NP, Halkos $M E$, et al. Neutrophil depletion reduces myocardial apoptosis and attenuates NFkappaB activation/TNFalpha release after ischemia and reperfusion. J Surg Res 2006;135:170-178.
15. Faeh D, Gutzwiller F, Bopp M. Lower mortality from coronary heart disease and stroke at higher altitudes in Switzerland. Circulation 2009;120:495-501.

16. Saunders PU, Pyne DB, Gore CJ. Endurance training at altitude. High Alt Med Biol 2009;10:135-148.

17. Millet GP, Roels $B$, Schmitt $L$, et al. Combining hypoxic methods for peak performance. Sports Med 2010;40:1-25.

18. Ahmad S, Ahmad A, Gerasimovskaya E, et al. Hypoxia protects human lung microvascular endothelial and epithelial-like cells against oxygen toxicity: role of phosphatidylinositol 3-kinase. Am J Respir Cell Mol Biol 2003;28:179-187.

19. Liu X, Wu X, Cai L, et al. Hypoxic preconditioning of cardiomyocytes and cardioprotection: phophorylation of HIF-1alpha induced by p42/ p44 mitogen-activated protein kinases is involved. Pathophysiology 2003;9:201-205.

20. Liu J, Narasimhan P, Yu F, et al. Neuroprotection by hypoxic preconditioning involves oxidative stress-mediated expression of hypoxia-inducible factor and erythropoietin. Stroke 2005;36: 1264-1269.

21. Bernhardt WM, Campean V, Kany S, et al. Preconditional activation of hypoxia-inducible factors ameliorates ischemic acute renal failure. J Am Soc Nephrol 2006;17:1970-1978.

22. Furuta GT, Turner JR, Taylor CT, et al. Hypoxia-inducible factor 1-dependent induction of intestinal trefoil factor protects barrier function during hypoxia. J Exp Med 2001;193:1027-1034.

23. Karhausen J, Furuta GT, Tomaszewski JE, et al. Epithelial hypoxiainducible factor- 1 is protective in murine experimental colitis. J Clin Invest 2004;114:1098-1106.

24. Robinson A, Keely S, Karhausen J, et al. Mucosal protection by hypoxiainducible factor prolyl hydroxylase inhibition. Gastroenterology 2008;134:145-155.

25. Yagihashi A, Tsuruma T, Tarumi K, et al. Prevention of small intestinal ischemia-reperfusion injury in rat by anti-cytokine-induced neutrophil chemoattractant monoclonal antibody. J Surg Res 1998;78:92-96.

26. Tsuruma T, Yagihashi A, Tarumi K, et al. Anti-rat IL-8 (CINC) monoclonal antibody administration reduces ischemia-reperfusion injury in small intestine. Transplant Proc 1998;30:2644-2645.

27. Simpson R, Alon R, Kobzik L, et al. Neutrophil and nonneutrophilmediated injury in intestinal ischemia-reperfusion. Ann Surg 1993;218:444-453.

28. Kuhl AA, Kakirman $H$, Janotta $M$, et al. Aggravation of different types of experimental colitis by depletion or adhesion blockade of neutrophils. Gastroenterology 2007;133:1882-1892.

29. Chen Y, Lui VC, Rooijen NV, et al. Depletion of intestinal resident macrophages prevents ischaemia reperfusion injury in gut. Gut 2004;53:1772-1780.

30. Schoenberg MH, Poch B, Younes $M$, et al. Involvement of neutrophils in postischaemic damage to the small intestine. Gut 1991;32:905-912.

31. Baxter GF. The neutrophil as a mediator of myocardial ischemiareperfusion injury: time to move on. Basic Res Cardiol 2002;97: 268-275.

32. Wijnen $\mathrm{MH}$, Vader $\mathrm{HL}$, Roumen RM. Multi-antioxidant supplementation does not prevent an increase in gut permeability after lower torso ischemia and reperfusion in humans. Eur Surg Res 2002;34:300-305.

33. Chan RK, Ibrahim Sl, Verna $\mathrm{N}$, et al. Ischaemia-reperfusion is an event triggered by immune complexes and complement. $\mathrm{Br} J$ Surg 2003;90:1470-1478.

34. Kevin LG, Novalija E, Stowe DF. Reactive oxygen species as mediators of cardiac injury and protection: the relevance to anesthesia practice. Anesth Analg 2005;101:1275-1287.

35. Hallett $M B$, Lloyds $D$. Neutrophil priming: the cellular signals that say 'amber' but not 'green'. Immunol Today 1995;16:264-268.

36. Matsuda A, Orihara K, Fukuda $S$, et al. Corticosteroid enhances TNFalpha-mediated leukocyte adhesion to pulmonary microvascular endothelial cells. Allergy 2008;63:1610-1616.

37. Hitomi Y, Miyamura M, Mori S, et al. Intermittent hypobaric hypoxia increases the ability of neutrophils to generate superoxide anion in humans. Clin Exp Pharmacol Physiol 2003;30:659-664.

38. Scannell G, Waxman K, Vaziri ND, et al. Hypoxia-induced alterations of neutrophil membrane receptors. J Surg Res 1995;59:141-145.

39. Wood JG, Johnson JS, Mattioli LF, et al. Systemic hypoxia increases leukocyte emigration and vascular permeability in conscious rats. J Appl Physiol 2000;89:1561-1568. 
40. $\mathrm{Yu} \mathrm{HJ}$, Chien $\mathrm{CT}$, Lai $\mathrm{YJ}$, et al. Hypoxia preconditioning attenuates bladder overdistension-induced oxidative injury by up-regulation of $\mathrm{BCl}-2$ in the rat. J Physiol 2004;554:815-828.

41. Yang CC, Ma MC, Chien CT, et al. Hypoxic preconditioning attenuates lipopolysaccharide-induced oxidative stress in rat kidneys. J Physiol 2007;582:407-419.

42. Lai IR, Ma MC, Chen CF, et al. The effect of an intestinal ischemiareperfusion injury on renal nerve activity among rats. Shock 2003;19:480-485.

43. Wu CC, Lu YZ, Wu LL, et al. Role of myosin light chain kinase in intestinal epithelial barrier defects in a rat model of bowel obstruction. BMC Gastroenterol 2010;10:39.

44. Wu LL, Chiu HD, Peng WH, et al. Epithelial inducible nitric oxide synthase causes bacterial translocation by impairment of enterocytic tight junctions via intracellular signals of Rho-associated kinase and protein kinase C zeta. Crit Care Med 2011;39:2087-2098.

45. Yu LC, Montagnac G, Yang PC, et al. Intestinal epithelial CD23 mediates enhanced antigen transport in allergy: evidence for novel splice forms. Am J Physiol Gastrointest Liver Physiol 2003;285:G223-G234.

46. Yang PC, Jury J, Soderholm JD, et al. Chronic psychological stress in rats induces intestinal sensitization to luminal antigens. Am J Pathol 2006;168:104-114.

47. Hsiao JK, Huang CY, Lu YZ, et al. Magnetic resonance imaging detects intestinal barrier dysfunction in a rat model of acute mesenteric ischemia/reperfusion injury. Invest Radiol 2009;44:329-335.

48. Bitzinger Dl, Schlachetzki F, Lindner R, et al. Flow-cytometric measurement of respiratory burst in rat polymorphonuclear granulocytes: comparison of four cell preparation procedures, and concentration-response evaluation of soluble stimulants. Cytometry $A$ 2008;73:643-650.
49. Russo-Carbolante EMS, Azzolini AECS, Polizello ACM, et al Comparative study of four isolation procedures to obtain rat neutrophils. Comp Clin Pathol 2002;11:71-76.

50. Mehrzad J, Klein G, Kamphues J, et al. In vitro effects of very low levels of aflatoxin $B$ on free radicals production and bactericidal activity of bovine blood neutrophils. Vet Immunol Immunopathol 2011;141: 16-25.

51. McGovern NN, Cowburn AS, Porter L, et al. Hypoxia selectively inhibits respiratory burst activity and killing of Staphylococcus aureus in human neutrophils. J Immunol 2011;186:453-463.

52. Nazli A, Yang PC, Jury J, et al. Epithelia under metabolic stress perceive commensal bacteria as a threat. Am J Pathol 2004;164:947-957.

53. Sekido N, Mukaida N, Harada A, et al. Prevention of lung reperfusion injury in rabbits by a monoclonal antibody against interleukin-8. Nature 1993;365:654-657

54. Kaneko $\mathrm{H}$, Tamura $\mathrm{A}$, Ishii $\mathrm{T}$, et al. Bacterial translocation in small intestinal ischemia-reperfusion injury and efficacy of anti-CINC antibody treatment. Eur Surg Res 2007;39:153-159.

55. Playford RJ, Belo A, Poulsom R, et al. Effects of mouse and human lipocalin homologues $24 \mathrm{p} 3 / \mathrm{lcn} 2$ and neutrophil gelatinase-associated lipocalin on gastrointestinal mucosal integrity and repair. Gastroenterology 2006;131:809-817.

56. Bernasconi E, Favre L, Maillard $\mathrm{MH}$, et al. Granulocyte-macrophage colony-stimulating factor elicits bone marrow-derived cells that promote efficient colonic mucosal healing. Inflamm Bowel Dis 2010;16:428-441.

57. Shifflett DE, Bottone Jr FG, Young KM, et al. Neutrophils augment recovery of porcine ischemia-injured ileal mucosa by an IL-1beta- and COX-2-dependent mechanism. Am J Physiol Gastrointest Liver Physiol 2004;287:G50-G57. 